\title{
Trinidad, creación y liberación
}

\section{Josep Vives, \\ Centro Borja, Sant Cugat del Vallés, Barcelona. Centro de Reflexión Teológica, San Salvador.}

La doctrina trinitaria presupone en el orden cognitivo la cristologia, pues sólo esta lleva al conocimiento y al concepto de Dios trino. Pero presupone una crisiología abierta; abierta al conocimiento de la creación del mundo por el Padre de Jesucristo y abierta al conocimiento de la transfiguración del mundo mediante el Espiritu Santo, que procede del Padre del Hijo Jesús. J. Moltmann, Trinidad y reino de Dios, Salamanca, 1985, 113.

\section{Para una teologia cristiana de la creación}

Uno de los últimos escritos que publicara Hans Urs von Balthasar -infatigable trabajador de la palabra hasta su muerte en fecunda ancianidad- se titula "Creación y trinidad". En él se pone de relieve lo específico de una concepción cristiana de la creación como acción en la que se realiza un designio libre y amoroso del Dios trinitario, frente a otras concepciones que pretenden explicar la realidad mundana como emanación o como resultado de un proceso dialéctico de autoposición del Absoluto. En este empeño - brillantemente realizado - muestra cómo una adecuada teología cristiana de la creación ha de girar primordialmente alrededor de los grandes textos del Nuevo Testamento que nos hablan de la creación en el marco del designio salvador de Dios. De distintas maneras, Pablo, Juan, la carta a los Hebreos nos hablan de la creación como obra del designio etemo de Dios Padre, realizado por el Hijo como mediador y como fin - "por el cual y para el cual todo fue creado" (Col 1 , 16) - con la fuerza de su Espiritu derramado sobre la tierra. La comprensión de lo que significa la experiencia salvílica en Cristo y en el Espíritu, Leva a los autores neotestamentarios a una nueva comprensión del sencido de la existencia del mundo y de la historia mundana. La leologia de la creación ya no podrá limitarse a ser una rellexión sobre "cómo fue el comienzo" de lodo a partir de Dios, sino que ha de pasar a considerar el sentido que todo ticne y ha de tener a partir de Dios y según el designio divino; no podrá limitarse a considerar la 
creación como un acontecimiento cosmológico pretérito, sino que tendrá que relacionarla con toda la realidad de la salvación entendida globalmente como acción histórica de Dios que comienza con la libre y amorosa posición del hombre en el mundo y culminará en la recapitulación de lodo en Cristo y en el electivo sefforío de Dios, "cuando él sea todo en Lodos" (1Cor 15, 28). Una mínima fidelidad a los textos del Nuevo Testamento nos lleva a no poder separar la protología de la soleriologia y de la escatología. Es a partir de lo que Dios quiere hacer con el mundo como hemos de entender teológicamente el ser del mundo. En los intentos de elaborar una teología de la creación, esta se limitó muchas veces a leer los relalos del Génesis sobre la falsilla de los mitos de las religiones o de las fillosofías - singularmente cl del Timeo platónico-, para seffalar ciertamente diferencias, pero dentro de una misma perspectiva "cosmológica", es decir, de curiosidad acerca de cómo comenzó el mundo. Más modemamente se leyeron los mismos relatos biblicos sobre nuevas falsillas de explicaciones pretendidamente científicas, con afanes ya concordistas ya condenalorios. El admirable estudio de L. Schefflczyk sobre la historia del dogma de la creación ${ }^{2}$ es en realidad la historia de la creciente incapacidad de los teólogos para ver la creación en el marco del designio salvador de Dios, y a la vez de su creciente obstinación en competir con cienúlicos y filósolos para explicar el origen del mundo. En los comienzos del cristianismo el gran Ireneo explica la creación desde la perspectiva del designio salvador de Dios que quiere llevar al hombre, a través de un proceso histórico de crecimiento, maduración y perfeccionamiento, a participar de su propia vida y de su inmortalidad. Esta perspectiva sigue presente en Origenes y en los Capadocios, aunque empieza a mezclarse con especulaciones que provienen más de las preocupaciones o prejuicios de la filosofía neoplatónica que de la atención a la revelación. Agustín retendrá todavía un fuerte sentido salvíficu aunque la controversia lo lleve a especular sobre "la nada" de la que Dios habría creado, o el tiempo contrapuesto a la etemidad e inmutabilidad de Dios. Especialmente la controversia antipelagiana llevará a separar cada vez más el opus creationis del opus redemptionis, -que dará lugar a la distinción de los tratados de Deo creante y de Deo elevante -, paralelamente a una concepción que creía poder distinguir adecuadamente un "orden natural" de un "orden sobrenatural" en el obrar de Dios.

Nadie discutirá que tales distinciones puedan tener sentido y aun puedan ser metodológicamente útiles. Lo que sí es cuestionable es que tales distinciones cum fundamento in re se trasladen a la realidad histórica y concreta como tal, como si histórica y concretamente hubiera una realidad de "creación" $\longrightarrow$ natural- que no estuviera ordenada a la "salvación" — sobrenatural-, de manera que pudiera darse adecuada razón teológica de una sin considerar la otra.

No es así como se presentan las cosas en los textos de la revelación. No sólo en los textos del Nuevo Testamento a los que me he referido, sino también en el 
mismo Antiguo Testamento se halla ya que la reflexión sobre la creación aparece en el marco de la reflexión sobre los fundamentos de la alianza y de la acción salvadora de Dios. Hace tiempo que los biblistas dejaron establecido que, aunque la Biblia tal como ahora la leemos comienza con el relato de la semana creadora de Dios, la concepción de Dios como creador no fue ni la más primaria ni la más determinante concepción de Dios en la religión de Israel. Para Israel Dios es, ante todo, protector y liberador del pueblo, Sefior de la historia y garante de su sentido. Dios de las promesas y de la alianza, Dios de los patriarcas, de Abraham, de Isaac y de Jacob. Se daba como por supuesto que si Dios era protector poderoso y eficaz de los hombres en el mundo, Dios era también Seftor del mundo; y hallamos textos antiguos que invocan a Dios como "creador del cielo y de la tierra": asl invoca Melquisedec al Dios Altísimo, bendiciendo a Abraham (Gen 15, 19 y 22). Pero la reflexión explícila sobre Dios como creador aparece a partir de la época del exilio. En el momento de esta experiencia en la que tambalea la fe en el Dios protector de Israel y en la eficacia de sus promesas, los profetas senalan los fundamentos de esta fe. Singularmente el llamado Deutero-Isaias explica que el "creador de Israel" es el "creador del mundo", y que el que es Sentor de todas las cosas, porque todas las cred, es también Sefhor del curso de la hisiria, y puede liberar a Israel de los que aparentemente dominan la historia, "porque tu esposo es creador, y tu salvador se llama Dios de toda la tierra" (Is 54, 5). El pueblo oprimido oye entonces esta palabra de esperanza libeadora: "Yo Yahvé lo he hecho todo; yo solo extendí los cielos, yo asenté la tierra sin ayuda alguna... Yo digo a Jerusalén: serás habilada" (Is 44, 24)3. Otros profelas se expresarán en términos semejantes, y esta reflexión dejará su impronta en los salmost. Es en el contexto de esta reflexión sobre el poder salvador de Yahvé, en tanto que Señor y creador de todas las cosas, que se articula, con elementos, en buena parte tomados de las cosmogonlas de los pueblos vecinos, el gran relato del autor sacerdotal sobre la semana creadora de Dios, que quedó colocado al comienzo de la Biblia En la misma estructura y movimiento del relaio, todo él orientado a poner de relieve la preeminencia del hombre sobre las demás obras de la creación, su responsabilidad en el uso y dominio de rodos y su peculiar relación con Dios como "imagen y semejanza" suya (Ex 1,26), se manifiesta ya que, más allá de un planteamiento "cosmogónico" o de explicación sobre el origen del mundo, el autor nos introduce en el ámbito propiamente teológico de la relación singular del hombre con Dios y de su responsabilidad ante Dios acerca del mundo. Verdaderamente el relato brblico inicial sobre la creación no es más que como un prologo o una introducción a los relatos sobre las promesas y la alianza. Nos indica no sólo cómo comenzó el mundo y el hombre, sino por qué y para qué; nos häbla ya no sólo del ser de las cosas, sino del sentido de la historia, de lo que Dios quiere que sea el mundo bajo la responsabilidad del hombre y en alianza del mismo Dios con el. Por esto se ha dicho certeramente: 
La fe del antiguo y del nuevo pueblo de Dios en la creación está transida de la experiencia de la alianza de Dios con Israel, alianza que llega a ser plena y defínitiva en Jesucristo. La relación que existe entre la economla salvifica y la creación no es la que existe entre dos acontecimientos que se suceden cronologicamente y nada más (el mundo como mero escenario de la salvación): la salvación es el acontecimiento en que se basa intrínsecamente la creación... Una creación desprovista de su función económico-salvifica, tratada únicamente como doctrina filosofica, no podria pertenecer a la teologla sino marginalmentes.

La doctrina cristiana de la creación va mucho más allá de las especulaciones fulosófico-científicas sobre el origen del ser del mundo. Su aportación específica consiste en declarar que no hay que explicar el mundo por un principio de necesidad intema de un priner principio, ya sea en esquemas emanatistas (neoplatonismo) o dialéclicos (hegelianismo'): el mundo se explica teológicamente sólo a partir de la voluntad libre del Dios trino, que quiere hacer al hombre como imagen de sí mismo y entrar en una relación de comunión gratuita con él, que es como una participación y reflejo temporal de la comunión de vida y de amor que constituye el mismo ser etemo de Dios, Padre, Hijo y Esplritu Santo. Lo que quisiéramos subrayar particularmente es que esta concepción de la creación libre como oferta de alianza igualmente libre y gratuita, no sólo está en los antípodas del emanatismo y de la supuesta dialéctica del Absoluto, (como muestra espléndidamente $\mathrm{H}$. U. von Balthasar en el artículo citado al comienzo), sino que reclama una teologla de la repuesia del hombre a la oferta libre de Dios. De esta forma, la teología de la creación, como oferta del plan del Dios Trino sobre el mundo y los hombres, ha de desembocar en una teologia de la salvación, que sera de hecho teologla del pecado y de la gracia, teologia del rechazo del hombre y de la poderosa ratificación de la oferta urinitaria con la muerte y resurrección de Jesús y la efusión de su Espíritu. Una teología en la que Dios triunfa de "la frustración a la que su creación se habla visto sometida" y se manifiesta "la liberación de la servidumbre de la comupción y la participación en la gloriosa libertad de los hijos de Dios" (Rom 8, 20-21). Si es verdad, como hace tiempo ensefian los teólogos, que la protologla anticipa ya la escatología y la precontiene, diríamos nosotros que la teologia cristiana de la creación anticipa y precontiene la teologla de la liberación. Negarlo sería negar sentido a la creación misma, y declarar fracasado al creador en su aventura creadora-salvadora?.

\section{La creación, obro ad extra de la Trinidad}

Los escritos del Nuevo Testamento nos presentan la creación como resultado de un designio del Dios trinitario y en el maro de la totalidad de la historia que abarca desde los comienzos, a través de las vicisitudes del devenir mundano y humano, hasta la consumación final. La palabra de Dios, inicialmente creadora, 
se hace presente y actuante en la historia, primero como palabra de promesa y de alianza, y, finalmente, como palabra salvadora de la creación. Es así como la misma palabra de Dios, increada y creadora, llega a hacerse por la encarnación en Jesús realidad creada y e infunde luego en la creación la fuerza transformadora de su Espíritu divino. De esta suerte, los textos neotestamentarios referentes a la creación resultan ser texios eminentemente cristológicos y también -aunque no de una manera tan explícitamente desarrollada-pneumatológicos. Tenemos así que en cl Nuevo Testamento se pone de manifiesto cómo la protología reclama la escatología y cómo ésta es algo que se alcanza a través de la identificación de la misma palabra creadora de Dios con su creación y de la acción de la fuerza del mismo Espíritu de Dios infundido en ella. Diríase que ya desde la primera reflexión sobre el significado de la experiencia salvifica en Cristo y en su Esplritu, los autores neotestamentarios (fundamentalmente Pablo y Juan, pero también otros ${ }^{b}$ ) descubrieron que si Cristo y el Espíritu salvan es porque tenían pleno sefiorío sobre lo que habla de ser salvado: no son salvadores extrafios, de fuera ("vino a lo que era suyo", porque "lodo fue hecho

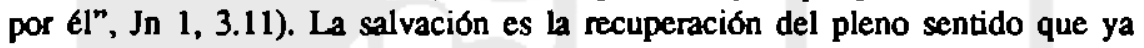
originariamente Dios había querido dar a su acción creadora, con una nueva acción de Dios - "nueva creación"- a través de su misma palabra y su mismo Espiritu.

Examinemos sumariamente algunos de estos textos. El más anliguo podría ser el de 1Cor 8, 6. En la polémica sobre la licitud de comer lo sacrificado a los ídolos, Pablo afirma que "el idolo no es nada en el mundo y no hay más que un solo Dios... el Padre de quien proceden lodas las cosas y para el cual somos; y un solo Señor, Jesucristo, por medio del cual son todas las cosas y nosotros también por él". En expresión densa y sintética el apóstol afirma a la vez: (1) que el último origen del mundo es Dios-Padre; (2) que el fin del hombre en el mundo es el mismo Dios Padre (nótese el cambio de expresión: Dios origen de "Lodas las cosas", pero lin de "nosotros", los hombres, con lo que se hace el tránsito de la "cosmogonía" a la "soteriologia"); (3) que el Senfor Jesucristo es el mediador o cuasi instrumento - diá- de la creación de todo; (4) y también mediador de nuestra creación y salvación. El Padre es así origen de todo y lin del hombre. Jesucristo es Señor, con el Padre, como mediador del Padre en la creación de todo y en la salvación del hombre. Es de notar que este mediador no es un mero Logos eterno, concebido a la manera filoniana: es Jesucristo, el que había sido visto en la tierra, Logos-encarnado, como mediador de la creación de todo es anterior a todo, preexistente con el Padre como instrumento suyo propio y divino en su acción creadora. Por esto se dirá de él que "siendo de condición divina.. tomó forma de siervo... hasta la muerte y muerte de cruz" (Fil 2, 5ss). Pero en virtud de su condición divina y de su tolal "obediencia" al Padre, Ja muerte no tuvo sobre él poder definitivo, sino que fue "exaltado" a su condición propia por la resurrección (Rom 1, 4). La primera carla a los Corintios $(15,23)$ 
af̂adirá más adelante: "Cristo resucitó como primicia; luego, los de Cristo en su (segunda) venida Después, al fin, entregará a Dios Padre el reino, una vez haya destruldo... hasla el último enemigo, la muerte... Cuando le hayan sido sometidas todas las cosas, también el Hijo se someterá a Aquel que le olorgó poder sobre todas las cosas, para que Dios sea todo en todo". Difícilmente podria expresarse con mayor énfasis y precisión la inextricable implicación que Pablo descubre entre protología, soteriología y escatologia, que viene del hecho de que uno y el mismo es el mediador del Padre en la creación, en la encamación salvífica por la que Dios mismo vence la muerte en el hombre, y en la consumación por la que todo se somete al designio originario del Dios Padre.

En la carta a los Colosenses hallamos más desarrollados algunos de estos temas. Si el autor utiliza un himno ya en uso en la liturgia de las comunidades, ello indicaría que la conciencia creyente habría captado ya plenamente la relación entre creación, cristología-soleriología y escatología, en el marco del ser trinitario de Dios (Col 1, 13-20). El autor da gracias al Padre, que nos ha llevado "al reino del Hijo de su amor, en quien tenemos redención, el perdón de los pecados". A manera de explicación de lo que constiluye este reino se nos ofrece una descripción de la obra del Hijo en la creación, la salvación y la consumación: "Todo fue creado por él y para él; él existe con anterioridad a todo, y wodo tiene en él su consistencia. El es cabeza del Cuerpo de la Iglesia (es decir, de los salvados). El es Principio (de la creación original) y el Primogénito de entre los muertos (de la nueva creación salvadora) para que en todo sea el primero. Dios tuvo a bien hacer residir en él toda la plenitud, y reconciliar por él y para él todas las cosas, mediante la sangre de su cruz, la tierra con los cielos". Aquf aparece Cristo, por don e iniciativa de Dios-Padre, como "Principio", mediador ("por él") y consumador ("para él", para "reconciliar") de todo en un designio único de Dios sobre "la tierta y los cielos".

La carla a los Efesios parece ofrecer una uterior elaboración de los mismos temas, con matices nuevos como la preelección eterna en Cristo para ser hijos suyos (Ef 1, 4-5); el designio de "recapitular en Cristo lo que está en los cielos y lo que está en la tierra" (Ef 1, 10); la realización de este designio por medio del "sello del Espíritu Santo de la promesa" (Ef 1, 13)9 y el cumplimiento en Cristo como "Plenitud que lo llena todo en todo" (Ef 1, 22).

La introducción a la carta a los Hebreos también relaciona en síntesis unitaria creación, salvación y consumación escatológica. Dios Padre ha hablado "úlumamente por medio del Hijo, por quien hizo los mundos, el que es resplandor de su gloria e impronta de su esencia, el que sostiene todo con el poder de su pajabra". Este mismo es el que, después de obrar la redención de los pecados, "ha sido sentado a la diestra de la majestad de Dios en los cielos, para reinar sobre todo" (Hbr 1, 1-8).

Es curioso que los escritos de Juan, que denotan una situación vital y 
cultural distinta de la de Pablo, tienen en el punto que comentamos una notable coincidencia de fondo, si no de forma. El prólogo del cuarto evangelio es también una presentación sintética de toda la acción de Dios en el mundo, en la cual se entrecruzan protología, soteriología y escatologla, esta última en forma de "doxología" o despliegue de la "gloria" del Padre. La Palabra que "se hizo came y puso su morada entre nosotros" es la misma que "existía en el principio y estaba con Dios y era Dios", aquella "por la cual se hizo todo, y sin ella nada se hizo". Por esto es una Palabra que "vino a lo que era suyo", aunque los suyos no la recibieran; pero a los que la reciben, los hace hijos de Dios y les manifiesta plenamente la gloria del Padre (ver Jn 1, 1-8). El resto del evangelio hay que leerlo a la luz de estas claves introductorias: particularmente, cuando Jesús se presenta como hablando sólo lo que el Padre quiere que obre o diga (Jn 5, 19-20, 8, 28-29), no nos parece que podamos comprenderlo fuera del contexto de la Palabra inicial creadora-salvadora de que hablo el prólogo.

A partir de estos texios paulinos y joánicos, fue habitual en la primitiva tradición cristiana considerar la creación como obra de la Trinidad, como despliegue de un designio amoroso que tiene su ráz en el mismo movimiento etemo con que Dios Padre se conoce y se ama a sí mismo y que quien libre y gratuitamente extiéndese y comunicase a la criatura "imagen suya" haciéndole gozar de su misma vida. En la época patristica se mantiene generalmente la toología de la creación en un marco trinitario y salvifico-escatológico, a pesar de la innegable interferencia de elementos inlerpretativos de origen filosófico, sobre todo neoplatónicos y estoicos ${ }^{10}$. A manera de muestra representativa sólo ofrezco un texto de aquel gran recopilador y sintetizador de la última época de la patristica que fue Juan Damasceno:

El Dios sobreeminentemente bueno no tenía bastante con la contemplación de sí mismo, sino que, por la sobreabundancia de su bondad, quiso que hubiera algo en que mostrara su benevolencia por la participación de su bondad. Es asi como saca las cosas del no ser a la existencia.. Crea en tanto que piensa, y su pensamiento subsiste como obra, que se realiza por su Palabra y se consuma por su Espíriul".

Básicamente, este texto plantea la consideración de la creación a partir de los elementos que proporcionaban los textos paulinos y joánicos, aunque estos elementos estaban elaborados en un marco neoplatónico, que el Pseudo-Dionisio habia introducido en el cristianismo. Sin embargo, la doctrina biblica rompe el esquema neoplatónico. Como observó bien $\mathrm{H}$. Urs von Balthasar ${ }^{12}$ el principio bonum diffussivum sui, entendido rigurosamente como un principio de necesidad, sólo parece sostenerse en una concepción emanatista: si el bien se difunde necesariamente, la creación ya no seŕa resultado de un acto libre de Dios, sino algo que fluye de Dios y como que se le escapa por necesidad: hay en realidad degradación del ser por emanación a partir del Uno. Pero los autores 
cristianos, comenzando por el Pseudo-Dionisio, dieron a aquel principio un sentido que rebasaba lo que entendfa el neoplatonismo. El principio podfa valer rigurosamente cuando se aplicaba al etemo y necesario dinamismo de la vida intratrinitaria de Dios. Dios-Padre es perfectamente bonum, y por eseo perfectamente diffussivum sui, etema y perfectamente se difunde y se comunica a una imagen perfecta de sI mismo, absolutamente igual a si en todo, menos en el hecho de ser comunicación; y en esta comunicación el bien primero no se pierde ni se disipa, sino que como que retoma a su origen en un nuevo bonum que es ya bien común del originante y del originado, y que, por eso, no puede ser simplemente ni el uno ni el otro. Ahora bien, esta "difusión" y autocomunicación de Dios eterna, necesaria y esencial, que constiuye lo que bien podemos llamar su vida trinitaria, es como la condición de posibilidad de su ulterior comunicación libre y graluila que resulta en la creación temporal, que es como un desbordamiento y una sobreabundancia de lo que ya constibúa el dinamismo propio autodifusivo de Dios. Dicho de otra manera, si Dios no tiene por sí y esencialmente un dinamismo autodifusivo, el movimiento de difusión de su ser que es la creación le advendría como algo accidental y ajeno a su propio modo de scr, cosa diffcilmente admisible. Si Dios no tiene otra comunicación que la que tiene lugar en la creación, entonces la creación le es necesaria a Dios para comunicarse, y Dios previamente a, o fuera de, la creación sería un ser incomunicado e incomunicable. Desaparece la idea, caracteristica de la Biblia, de una creación libre; y se recae en el modo gnóstico que pone en el principio "el silencio" en "el abismo." Pero si en el principio no hay más que el silencio, no se puede explicar cómo jamás, o de dónde, pudo surgir la Palabra creadora de realidad inteligible. Por esto no queda otro camino que poner in capise -como lo hizo el cuarto evangelio, seguramente en consciente oposición a la miblogía gnóstica- que "en el principio era la Palabra, y la Palabra estaba con Dios y la Palabra era Dios". Si no hay Palabra eterna, plenamente autocomunicativa, no puede haber Palabra productora de realidad temporal y parcial. Si no hay al principio cl etemo Bien absoluto y autosuficiente, con absoluta e incondicionada comunicación eterna de sI mismo, no habrá comunicación alguna de bien parcial o temporal. La criatura bien podrá ser una "dicción" de Dios, pero no puede ser la "dicción" propia y esencial de Dios. Si Dios no tiene otra expresión o dicción que la que resulta en la realidad, ciertamente imperfecla y finita de la creación, habria que declarar que Dios es limilado e imperfecto en su comunicación, o que no se comunica para nada, como aquella solitaria "Mente Suprema" de Aristóteles, que sólo puede conocerse a sI misma y que extraflamente lo mueve todo sin conocer nada. Si tanto el Arcopagila como el Damasceno van más allá del aristotelismo y del neoplatonismo -aunque utilicen sus categorias mentales- es porque a la luz de la Biblia han conocido al Dios vivo como etema aulocomunicación trinitaria; eterna "aulodifusión" del bien, que puede resultar en "bienes"; eterna Palabra perfecta que puede resonar como Palabra creadora; eterna Imagen total y 
adecuada, de la que pueden derivar imágenes parciales y finitas. Eslo es lo que quieren decir cuando hablan de "la sobreabundancia" de su bondad, o de la gratuidad en libertad de "su benevolencia".

De esta manera, la tradición patrística oriental, que está representada en Juan Damasceno, mantiene el enfoque trinitario-salvífico al considerar la creación a través del esquema neoplatónico del bien difusivo de sí mismo. La tradición occidental olvidó pronto esta perspectiva, que habia sido también la de Ireneo y Tertuliano. Agustín había sufrido el influjo ncoplatónico quizás tanto como el Areopagita, pero su espíritu penetrante y metafísico lo llevó a subrayar más la unidad del primer principio que la lorma y las condiciones de su comunicación. A ello pudo contribuir, por una parte, la reacción contra toda forma de subordinacionismo que acechaba siempre en los intentos de verter el cristianismo en categorias neoplatónicas; y por otra, la reacción contra el dualismo maniqueo, del que el mismo Agustín habia sido víctima. En consecuencia Agustín se afana en defender - y este es el programa de su De Trinitate - que las tres personas que nos propone la fe no son sino un único Dios, y que este Dios único es el creador del universo' ${ }^{13}$. Mientras que los griegos, con un enfoque más dinámico e histórico-salvílico, partian de Dios-Padre y declaraban que el Hijo y el Espíitu le eran consubstanciales en tanto que comunicación perfecla de la misma vida y bondad infinitas del Padre, Aguslín, con un enfoque más especulativo y metafísico, parte de la divina sustancia única que es "Dios" y quiere mostrar que Padre, Hijo y Espíritu son un solo Dios en tanto que se identifican con esta divina esencia única. Cenurando así su atención en la unidad de Dios como supremo principio de todo - contra maniqueos y politeístas - e intentando explicar sobre todo cómo la trinidad de personas que propone la fe no atenta contra aquella unidad -contra amianos y uriteístas-. Agustín elabora su sutil concepción de la esencia o sustancia de Dios como trimelacional, explicándola luego por referencia a las conocidas analogías psicológicas. Pero en su insistencia en la unicidad y unidad de Dios parece dejar de lado la economía trinitaria en la misma creación, tal como la hemos visto subrayada en los escritos paulinos y joánicos ${ }^{14}$. Se escandaliza con razón contra el subordinacionismo arriano:

La trinidad es un solo Dios; y así como es un solo Dios, es también un solo creador. ¿Qué es lo que dicen esos (los arrianos), que el Hijo creó todas las cosas por mandato del Padre, como si el Padre no hubiera creado, sino que sólo hubiera mandado al Hijo que creara?... Se imaginan que se trata de dos sujetos, que, aunque estén juntos, cada uno tiene su lugar, y uno manda, mientras que el otro obedece ${ }^{15 .}$

Con coda razón rechaza Agustín esta idea arriana de "dos sujelos" en subordinación, estableciendo que "Padre, Hijo y Espíritu, así como son inseparables en el ser, también lo son en el acuar"16. Pero lucgo Agusún habla de 
"La inseparable acción de una e idéntica sustancia"17; y tambiên alirma que:

Todo lo ha llevado a término loda la trinidad, no como si cada una de las personas fuera impotente para hacerlo sin las otras, sino porque no puede dividirse la acción alli donde la naturaleza no sólo es igual, sino también individida... y toda la trinidad es sólo un Dios ${ }^{10}$.

Cabe replicar que en cicrto sentido sí hay que alimar que "cada una de las personas es impotente para hacer nada sin las otras", ya que ni siquiera puede subsistir sin las otras. Más exacto sería decir que las personas, así corno subsisten en correlación esencial y necesaria, as lambién acuian en correlación esencial y necesaria; y así la obra de la creación es, ciertamente, obra de toda la Trinidad, pero no de "la sustancia divina", o del "Dios único" indiferenciado, sino del Dios que es Padre, que se comunica por el Hijo que es su PalabraImagen ( $y$ sólo porque liene esencialmente esa Palabra-Imagen puede comunicarse) en el Espíritu, en el que se recoge y consuma toda comunicación del Padre.

La tendencia a auribuir la acción creadora de Dios a la "sustancia" o a la "naturaleza" divina, considerada en abstracción de su tripersonalidad, se fue a fianzando en la teología latina. La escolástica formuló el principio de que "las acciones ad extra son comunes", lo cual se entendio, no en el sentido correcto de que las tres personas no actúan ad extra "separadamente", sino en el sentido de que la trinidad de personas es irrelevante en la operación ad extra de Dios. San Anselmo, defendiendo, con razón, que Padre, Hijo y Espíritu no son "tres principios", sino un sólo principio creador, argumenta que "son creadores en virtud de aquello en que son uno, no en virtud de aquello en que son tres"'9; es decir, crean en tanto que son de naturaleza divina (única) no en tanto que personas distintas. Sin embargo, esta manera de atribuir a la naturaleza divina la potencia creadora como independientemente de y previamente a las personas parece cuestionable: porque la naturaleza divina puede crear en tanto que es una naturaleza esencial y necesarianente autofecunda y autocomunicativa, y, por tanto, esencial y necesariamentc Padre-Hijo-Espíriu. No es exacto decir, con Anselmo, que los tres "son creadores en virud de aquello en que son uno, no en virtud de aquello en que son tres", sino que sería más correcto decir que son creadores porque son uno con una forma de unidad autofecunda y autocomunicativa, que exige y requiere la Trinidad.

Es aqui donde se manifiesta la diferencia entre la teología latina y la teología griega de la Trinidad. Los latinos tienden a contraponer la esencia divina a las personas, consideradas meramente como oposición de relaciones dentro de la divina esencia, lo cual no afectarían, por tanto, la acción ad extra de Dios. El concilio de Florencia, con su axioma "en Dios todo es uno donde no obsta la oposición de relaciones" 
de Dios no afecta la oposición de relaciones intradivinas, luego es algo que hay que referir a la unidad esencial de Dios. Pero no es asl como lo ve la teología griega, más fiel a la Biblia que a la filosofia del Uno: la acción creadora de Dios sl tiene que ver con la oposición de relaciones, porque no es la acción de un "Dios-Uno" indiferenciado, sino que es la acción del "Padre", que pucde actuar porque es principio autofecundo de comunicación que se comunica etemamente con su Palabra-Imagen y se reencuentra con su Espíritu. Así lo vela Alanasio:

El Padre, por medio de su Palabra y en el Esplritu es creador de todo. Es asl como queda asegurada la unidad de la Santa Trinidad. y como la Iglesia predica un único Dios, que es sobre todo, en todo y por todo; sobre todo como Padre, principio y origen; por todo como acción de la Palabra; en todo en el Espíritu Santo. La trinidad no es asl sólo un nombre, o una palabra sin contenido, sino que es Trinidad con realidad y consistencia propia ${ }^{21}$.

El P. Th. de Régnon comentaba que en la teologla griega "las personas intervienen en el acto creador, no simplemente por vía de identidad sustancial, como en la teologla latina, sino formalmente, distintamente, con su carácter personal $^{\text {"22 }}$. La postura latina deriva, en parte, de la tendencia a considerar en la acción creadora la acción de Dios meramente como causa eliciente, sin atender a la causa ejemplar y final que, según los textos bóblicos aducidos, sólo se puede entender en el marco de la participación ad extra de la misma vida trinitaria de Dios. La causa ejemplar de la creación es la participación de su Sabiduria mediante la Palabra del Padre; y su causa final es su Amor, que derramado por su Espiritu, levanta a la criatura hasta la participación de la misma vida inefable que es la trinidad de Dios.

Santo Tomás participa del mismo enfoque latino, por eso puede decir que "la virtud creadora de Dios es común a toda la Trinidad" y "pertenece a la unidad de la esencia, no a la distinción de las personas"z. Sin embargo, más adelante matizará su pensamiento:

Crear le conviene a Dios según su propio ser, que es su esencia, la cual es común a las tres personas. Por lo cual crear no es algo propio de alguna de las personas sino algo común a loda la Trinidad. Sin embargo, las personas divinas, según la razón de su propia procesión, ejercen causalidad en la creación de las cosas... Porque Dios es causa de las cosas por su intelecto y por su voluntad.. Y asl las procesiones de las personas son causa de la producción de las criaturas.

Y, resolviendo objeciones, antade en el mismo articulo:

Así como la naturaleza divina, aunque común a las tres personas, les conviene según un delerminado orden, ya que el Hijo la recibe del Padre, y el Espíritu la recibe de ambos, así también la virtud creadora, aunque común a las tres personas, les conviene según determinado orden, ya que el Hijo la 
recibe del Padre, y el Esplriu la recibe de ambos. $Y$ así se auribuye al Padre el ser Creador, en tanto que no recibe de otro la virtud Creadora. Pero el Hijo, "por quien fueron hechas lodas las cosas" tiene la misma virtud, pero recibida de otro. Y al Espirim, que tiene la misma virtud de ambos, se le atribuye el gobemar y vivificar como Seflor lo que fue creado por el Padre mediante el $\mathrm{Hijo}^{24}$.

El planteamiento es correcto, aunque se mantiene a un nivel excesivamente formal. Por ello sólo desemboca en una consideración de las "atribuciones" de cada una de las personas de aquello que propiamente sigue considerándose como "propio" de la esencia divina. Habría que ir más alta hasta decir no que "crear le conviene a Dios según su propio ser, que es su esencia" (ya que el ser real y concreto de Dios no es su esencia abstracta, sino su esencia comunicada en trinidad de personas), pero si que crear le conviene al Padre en tanto que es capaz de comunicar su ser y su bien, y por tanto en tanto que tiene una Palabra etema que puede ser Palabra creadora, y en tanto que puede amar con un Amor etemo que puede extenderse gratuitamente a las criaturas; es decir, la esencia divina es creadora no porque es la esencia de un supuesto Dios-uno, absoluto e indiferenciado, sino porque es la esencia del Dios autofecundo que exige desplegarse en trinidad de real y efectiva comunicación, de la cual la creación es como una prolongación y extensión analógica libre y gratuita.

El mismo Santo Tomás parece haberlo vislumbrado ya asf. Cuando se plantea la cuestión de si podemos llegar a conocer la Trinidad divina por la razón natural, responde negativamente, ya que la razón solo llega a Dios como causa de lo creado. Sin embargo, respondiendo a las objeciones admite que el conocimiento de la tripersonalidad divina, que no nos es dado más que a partir de la revelación,

es necesario para poder llegar a una concepción correcta de la creación. En efecto, cuando decimos que Dios lo hizo todo con su Palabra se excluye el error de los que dicen que Dios lo produjo todo por necesidad de naturaleza; y cuando ponemos en él la producción por amor, se pone de manifiesto que Dios no crea por alguna indigencia suya, ni por causa alguna extrínseca, sino por el amor de su bondad"s.

Es decir, serfa excesivo pretender deducir la Trinidad por razón a partir de la creación; pero a la vez hay que afirmar que no se alcanza una correcta concepción de la creación más que a partir de la revelación de la Trinidad. Y ello es asl porque hablar de un Dios creador es hablar de un Dios "personal", no de un principio metafísico o de una causa flsica que actúase por necesidad; es hablar de un Dios libre y autocomunicativo, que es "Palabra" y es "Amor": y este Dios solo es el Dios trinitario de la revelación.

La escuela franciscana se interesó más particularmente en mostrar la relación entre la vida trinitaria de Dios y su acción creadora. Buenaventura dice que 
el Padre engendró al que era igual a sí mismo, es decir, su Palabra coeterna consigo; y dejó una semejanza de sí, que tuvo como consecuencia expresar todas las cosas que estaban en su poder ${ }^{25}$;

por lo cual, aflade: omnis creatura clamat aeternam generationem ${ }^{27}$. Un comentarista franciscano resume asi la doctrina de San Buenaventura: "la creación es una prolongación analógica de la generación eterna del Hijo. La criatura lleva en sl, en su puro ser natural, el sello de la filiación...; es potentia oboedientialis para la gracia sobrenatural de la filiación. Toda criatura es un eco del Hijo, y está encauzada a él...; es Verbum Patris en el tiempo"m. Se comprende que la escuela franciscana mantuviese que la creación está ya orientada por sí misma a la encamación, independientemente de la caída y del decreto de redención, sin que ello comprometa ni la gratuidad del orden sobrenaural, ni la libertad del decreto encamatorio. Se trataba de ampliar el horizonte más allá de la consideración de Dios como causa eficiente del mundo, para alcanzar un insellectus fídei más adecuado de la creación como realización de un designio divino que surge de la autocomunicación amorosa de ser, de bien y de vida que se da en la trinidad de Dios.

Lo que realmente está en juego es la preservación del genuino concepto bíblico de creación. Sólo un Dios "personal" autocomunicalivo de si puede crear realmente. Un Dios concebido como Supremo Principio a-personal no podría crear, porque la creación es el don personal y libre de Dios a un "otro", pero de tal manera que este "otro" no es aquel en quien única, per se y necesariamente se realiza la comunicación personal de Dios. Dios tiene su propio "Otro" -con mayúscula-, eterno y necesario; y por esto puede desplegarse en comunicación a "otros" imagen y participación de su "Otro". Si la única comunicación de Dios fuese la criatura, Dios sólo devendría comunicativo y personal con la misma creación, a la manera hegeliana. Pero, entonces, la creación sería esencial a la comunicación de Dios, serla la autorrealización de Dios mismo, y ya no podrán distinguirse adecuadamente Dios y la criatura Frente a la metaftsica de la emanación apersonal y necesaria, o de la autoposición dialéctica, igualmente necesaria, del Absoluto en la nada, la Biblia nos lleva a una metafisica de un Dios personal, que, realizándose plenamente como tal en su comunicación esencial y necesaria a un "Otro", imagen perfecta y divina (correlato de la eterna comunicación del eterno "Yo" divino, a un "Tú" igualmente divino, que resulta en un "Nosotros" igualmente divino), puede, libre y gratuitamente, ampliar su comunicación a otros "tú", y establecer con ellos un nuevo y gratuito "nosotros". Por eso sólo bajo la concepción de un Dios personal y urinitario -tripersonal- puede hablarse de creación. Y lo confirma el hecho de que las especulaciones metafísicas que no piensan a Dios trinitariamente, en realidad, desembocan en el emanatismo o en la autoposición necesaria de Dios en la realidad mundana. Así lo ha visto un tcólogo latinoamericano, en un libro que merece atenta consideración: 
La creación es don personal de Dios. Partiendo de la distinción conceptual (absolutamente inadecuada) entre naturaleza divina y personas divinas, diríamos que la creación no tiene que ver con la naturaleza, sino con las personas... No seriamos ni de su naturaleza, ni un producto hecho por ella. Scriamos más bien el don de cada una de las personas. En sus relaciones mutuas Dios crea por su Hijo en el Espiritu; y en el Espíritu la creación se ofrece al Padre por Jesús. Al "final" del proceso ha habido, pues, un cambio, es decir, algo que "antes" no existia: lo creado tiene en Jesús la misma gloria (consistencia) de Dios: ha sido asumido por Dios en sus relaciones personales. Forma parte de la comunidad de Dios, pero manteniéndose como distinb, como creado... es decir, como exterior, como libre ${ }^{29}$.

\section{Creación, historia y liberación}

Serfa equivocado pensar que lo expuesto liene sólo un interés metafísico o teologico abstracto: afecta muy radicalmente nuestro existir como criaturas, nuestra manera práxica de vivir crealuralmente en relación con Dios y en relación con los dernás hombres y con el mundo.

Lo primero que debiéramos señalar es que, de lo que hemos ido considerando, resulta que la Biblia no nos presenta tanto a Dios como creador del cosmos cuanto como creador de la historia. Esto es lo que se quiere decir cuando se afirma que en la Biblia la crcación es el "pre-supuesto" (W. Kern) o el "fundamento extrínscco" (K. Barh) de la alianza. Al Dios de la Biblia no le interesa "crear cosas", sino poner en marcha la historia. "La creación no es un mero hacer existir, sino hacer existir en un marco de gracia, en una estrucura salvífica"30. G. von Rad explica asi que Israel no tuviera un equivalente al concepto griego de "cosmos", que vendria luego a enturbiar la reflexión cristiana sobre la creación:

Israel no se hallaba en la situación de concebir el mundo como una magnitud filosofica objetiva, a la que se ve contrapuesto el hombre. Para Israel el mundo no era un ser, sino un acontecer... Israel no consideraba el mundo cono un organismo estructurado que descansa sobre sí mismo, pues por un lado veía a Yahvé que actuaba de una manera inmediata en los acontecimientos del mundo, y por otro lado el hombre reconocía su propia participación en la historia ${ }^{31}$.

En un mundo cultural y socialmente fixista e inmovilista, extroverido además hasta el punto de dar más valor a las cosas que el hombre puede manipular y utilizar que al sentido de la propia realidad humana, se hizo fuerte la tendencia a ver el acto creador como una acción de Dios que quedaba al principio y csiatlecía un orden permanente y definitivo que habia que respetar tanto a nivel de raluriteza como a nivel de sociedad. Reconocer al creador era acatar el ordci cstablecido. Esta es la idea de Dios creador a la que se agarran 
wodos los conservadurismos y a la que la misma Iglesia ha pagado - y sigue pagando - un excesivo tributo. Cieramente, Dios es el creador de la naturaleza en la que ha dejado como impronta de su sabidurla unas "leyes naturales" que no se pueden ignorar impunemente. Pero Dios creó la naturaleza como abierta a la historia, a la responsabilidad y a la decisión libre del hombre sobre la naturaleza, que es el que puede y debe darle sentido, - y desgraciadamante puede también frustrar su sentido y razón de ser; y abierta también a la acción del mismo Dios en la naturaleza y en la historia.

Esto es asl porque al principio de todo no hubo un principio de Necesidad, sino un acto libre del Dios personal, quien con su Palabra creó al hombre a su propia imagen -es decir, personal, inteligente, libre, responsable - en un designio para entrar en relación amorosa con él hasta elevarlo a participar de su propia vida, de su gozo y de su gloria por la comunicación de su propio Esplritu divino. Es en la teologí trinitaria de la creación donde aparece cómo Dios no crea ni por pura necesidad interna, ni para obtener algo que le faltara, sino para comunicarse libre y gratuitamente, para entrar en relación con "otros" que son imagen del "Otro" que es término esencial y eterno de la comunicación divina; y para terminar en un "Nosotros" en el cual Dios y cl hombre, manteniendo su radical distinción, se unen en el gozo de la comunión.

La creación del hombre es como la propuesta que Dios le hace de entrar en comunión amorosa con el desde su condición y situación humana, en la libre disposición de sí mismo y en el uso de las cosas mundanas. Es así como surge la historia, como ambito donde el hombre responde - positiva o negativamentea esta propuesta y ofera. La hisloria presupone liberad; en un mundo de pura necesidad no habria historia, habria la inexorable y fatal repelición de siempre lo mismo. Pero la historia presupone también un fin, una meta, un bien último a alcanzar por la libertad. Ser libre significa no sólo estar libre de condicionamientos extrónsecos, sino a la vez ser libre para optar por algo que uno pueda reconocer como su verdadero bien. La libertad se juega dialecticamente entre la ausencia de necesidad extrinseca (libertad de) y la interpelación para conseguir un bien verdadero (libertad para), cuya consecución tiene sentido y valor para el agente libre. La capacidad para hacer varias opciones, pero en forma tal que no se pudiera atribuir mayor o menor valor o sentido a una y otra de ellas, sino que imporlase lo mismo una que otra, reduciría la libertad a mera indeterminación y serfa la negación del hombre como ser responsable. Me gusta la manera como la expresaba N. Berdiaeff:

La historia presupone... una correlación entre el designio divino sobre el mundo y la verdadera libertad del hombre interpelada por aquel designio divino. Si solo existiera el designio divino y la liberad divina, resultaría una ineluctibilidad natural que serfa la negación de la historia. Si sólo existiera la libertad humana, sin interpelación ni norma superior a ella, tampoco existiria 
propiamente una historia, sino sólo la errática sucesión de acontecimientos provocados por aquella liberiad. Hay historia porque el hombre puede llevar los acontecimientos a la consecución o al fracaso de un fin querido por Dios, es decir, absoluto ${ }^{32}$.

Dios no ha creado el mundo como un gran mecanismo perfecto, el cual solo puede funcionar según las previsiones de su gran Arquitecto o Ingeniero. El mundo como obra de la Trinidad, como don personal de Dios que crea al hombre personal a imagen suya y quiere establecer con el una comunión libre y gratuita, es el ámbito en el que Dios mismo se atreve a jugar, por así decirlo, la aventura de la libertad del hombre. Decir, con el texto que acabamos de citar, que el hombre puede llevar "a la consecución o al fracaso de un fin querido por Dios, es decir, absoluto", podria parecer paradojico y hasta blasfemo. LEs que el hombre puede hacer fracasar el designio divino? ¿No es esto poner al hombre por encima de Dios? ¿No es imaginar la creación como una obra de aprendizaje de brujo que se revuclve contra su autor?

Y sin embargo, la Biblia nos obliga a tomar en serio este lenguaje. Dios crea el mundo con un designio que se ha de realizar a través de la libertad humana. La creación es el aclo libre, gratuito y amoroso de Dios que ofrece al hombre comunicación, igualmente libre, gratuita y amorosa, y espera, en real y efectivo respeto a la libertad humana, una respuesta humana positiva. La creación es "promesa", es "alianza", es interpelación: nunca es mera imposición. Es verdad que Dios es Seffor de la historia pero no con un sefiorfo que anulase la libertad y la responsabilidad del hombre, sino con un seflorfo que suscita, posibilita, orienta y da sentido a esta responsabilidad, sin janás aplastarla o anularla:

La acción de Dios se realiza en y a través de la libertad humana por ella sustentada; el ejercicio auténtico de esta libertad es el lugar privilegiado en el que se transparenta Dios como fuente de energla que suscita y como polo de amor que atrae... En el origen de su historia.. y en los mismos avatares de su decadencia... Israel descubrió la presencia activa de Dios. En el trabajo único de la propia liberlad iba viendo a alguien más grande que esa libertad: como fuente, guía, correctivo y promesa de la misma ${ }^{33}$.

Este es el Dios que nos está redescubriendo la teologla de la liberación, más allá del Dios de la teología de la ilustración. El Dios de la Biblia no es simplemente el Dios que lo puede todo o que lo explica todo, y que, por tanto, es único responsable de todo, subsumiendolo y anulándolo todo bajo su poder. El Dios de la Biblia, creador personal para un designio de comunión personal con el hombre en el mundo, es principio primero que constituye y posibilita la libertad humana, la orienta y atrae como bien absoluto, la interpela y la juzga como critcrio supremo de valor.

Ahora bien, la historia humana -de la cual la historia de Israel, narrada en la Biblia, no es más que como una muestra representativa - aparece desde los 
comienzos como una historia de frustración del designio divino $y$, consiguientemente, como frustración del mismo hombre en su existencia mundana. La humanidad se precipitó en to que teológicamente se llama "pecado" que es a la vez rechazo de la oferta de Dios y autodestrucción del sentido y de las posibilidades del hombre en su existencia humana. A través de mitos y tradiciones antiquísimas (caída en el paraiso, Caín y Abel, la torre de Babel, el diluvio) y a través de la predicación profélica y, ya en el nuevo testamento, de reflexiones como las que encabezan la carta a los Romanos, la Biblia es testimonio privilegiado de lo que, por otra pare, es trágica experiencia universal: la historia de la humanidad es una historia de maldad, de perversidad, de sufrimientos, de miserias y de muerte. Parece como que, desde los mismos comienzos, a Dios se le hubiera maltrecho la creación, y como si el pecado y el mal, acumulándose y multiplicándose sin cesar, hubieran frustrado totalmente el designio originario.

¿Habrá que declarar simplemente que, como el hombre ha rechazado la oferta y propuesta primera de Dios, Dios lo abandona a su suerte y a su frustración definitiva? Toda la Biblia, así como es testimonio de la frustración del hombre pecador, es todavía más testimonio de la firme voluntad de Dios para recuperarlo. para reconducirlo, para salvarlo, recuperando asi el sentido de toda la creación. La Biblia es sobre tado propuesta y oferta de salvación. propuesta y oferta para recuperar el sentido de la creación y del hombre, de hacer une nueva creación en la cual se realice el designio originario, es decir, que se manifieste la gloria y el gozo de la Trinidad al hacer que los hombres vivan entre sí y con Dios en una comunión de vida semejante a la que consiluye la vida misma y la gloria misma y el gozo mismo de Dios.

Ahora bien, la recuperación y la salvación de la creación, si ha de ser verdaderamente tal, ha de ocurrir en las mismas condiciones originarias de la creación, es decir, en la historia y en la liberiad. La "nueva creación" será nueva en el sentido de que en ella ya no se manifestará la frustración que se manifestó en la primera creación, pero no en el sentido de que sea un ámbito distinto de realidad que nada tenga que ver con el primero. Se trata de "salvar", de "recuperar" o "restaurar" la acción primigenia, no de echarla por la borda y sustituirla por otra cosa Y, sobre todo, se trata de salvar la originaria "imagen de Dios", la liberiad y la responsabilidad del hombre, reconduciéndolo a reconocer el proyecto primigenio de Dios y dándole fuerza para seguirlo libre y amorosamente. La nucva creación será salvación en gracia y libertad-lodo don es de Dios, pero loda la responsabilidad es del hombre- para que efectivamente sea salvación del hombre y de la historia y no una mera eliminación — alienación- del hombre y de la historia con el opio de una promesa de compensación ultramundana y metahistórica. Como ha dicho $\mathrm{I}$. Ellacura 
lo que importa es determinar el carácter historico de esta salvación: si, en efecto, la historia de la salvación es una salvación en la historia, o solamente más alká de la historia ${ }^{34}$.

Me apresuro a affadir, para prevenir la casi inevitable objeción - a veces ingenua y a veces malévola- de "reduccionismo", que afirmar que se ha de dar salvación en la hisloria no implica alurmar que no hay más salvación que la intra-histórica. Lo que se afirma es que, si no hay salvación en la historia no hay propiamente salvación de la historia (a menos que se entienda como salvación la hulda de la historia, como proponen ciertos sistemas alienantes de salvación). Lo que queremos decir es que Dios se reafirma en su originario proyecto creador en cuanto que su imagen resplandezca en el hombre dentro de sus condiciones propias -históricas- para sumirlo más allá de la hisLria en la comunión de su vida trinitaria Y la manera como Dios realizará la salvación de la historia en la historia será mediante el envío o "misión" a la historia mundana de su misma Palabra creadora, y la "efusión" de su mismo Espíritu de comunión como liberador $e$ inspirador de la libernad humana.

Esie es el argumento definilivo para creer que Dios quiere hacer efecliva ya en la historia la salvación que ha de consumarse en la metahistoria: Dios se ha comprometido con la historia hasta enviar a su Hijo-Palabra y a su Espíritu santificador a la realidad histórica, que parecía abocada a la comupción y al sinsentido, para transformarla. Nos hallamos aquí ante lo que constituye el núcleo más central del mensaje cristiano, que es que, en Jesús y en el Espíritu, Dĭos quiere "recuperar lo que se le había perdido" (Lc 19, 10); que "tanto amo Dios al mundo que le entregó su hijo unigénito... porque Dios no ha enviado a su Hijo al mundo para condenar al mundo, sino para que el mundo se salve por él" (In 3, 16-17); que "tenemos una esperanza que no falla, porque el amor de Dios ha sido derramado en nuestros corazones por el Espíitu Santo que nos ha sido dado" (Rm S, 5), que no es "un espíritu de esclavitud que nos hace recaer en el temor, sino un espíitu de hijos adoptivos que nos hace clamar 'Abba, Padre', y se une a nuestro espíritu para dar testimonio de que somos hijos de Dios" (Rm 8, 15-16; ver Gal 4, 4-7).

Lo que se nos revela en el "envío" o "misión" del Hijo y del Espíiu es que Dios ama tanto a este mundo nuestro y a esta historia nuesura que, aun después que los pecados de los hombres parecían haber Irustrado su designio originario, quiere recuperar su sentido haciendo con ello una gran ostentación de su gloria. Quiere salvar nuestro mundo y nuestra historia humana como desde dentro, recuperando y transformando su propio ser, no simplemente sustituyendo la antigua creación corrompida por otra distinta, ni simplemente prometiendo la salvación en un más allá a los que logren escapar incontaminados de este mundo.

Lo propio y espectlico del cristianismo es que la salvación se juega en este 
mundo y es verdaderamente salvación del mundo y en el mundo, gracias a Jesús, Hijo de Dios, enviado al mundo, y al Espíriu, derramado en el mundo. En este sentido to que Jesús proclama y anuncia es la llegada del "reino de Dios" (Mt 3, 2; 4, 17; Lc 17, 20-21) que no es algo meramente fuluro, y menos aún puramente melahistórico, sino que, al contrario, "está cerca", "en medio de ustedes", y constituye una "buena nueva", ya de inmediato, para los pobres, los oprimidos y los pecadores (Lc 4, 18-19; Mt 11, 3-6, etc.). El reino que Jesús proclama e imagina, y al que invita a sus seguidores, explicándolo con sus parábolas, es una nueva presencia y acción de Dios en el mundo y entre los hombres mediante la cual Dios quiere recuperar el designio originario de la creación (salvación del mundo). Pero, siendo originariamente un designio amoroso y gratuito, su recuperación será igualmente amorosa y gratuila: la salvación no es una imposición, es una nueva oferta, una invilación a la conversión (Mt 3, 2; 4, 27), una interpelación a la responsabilidad y generosidad (parabolas del sembrador, de los administradores, de los invitados al banquete, Mt 21, 33-43; 25, 14-29; Lc 14, 15-24, etc.). Quizás nada expresa mejor lo que es el reino que la oración que Jesús enseñó a los suyos, que bien podría llamarse la "oración del reino" (Mi 6, 7-15; Le 11, 2-4). "El Reino es la comunidad de los que reconocen a Dios como "Padre nuestro" —de todos-, "que está en los cielos" - con seflorio y transcendencia-; Padre de los que quieren que su nombre "sea glorificado" —y no "blasfemado" por la mala conducla de los hombres (ver Ez 36, 22-23)-, procurando hacer su voluntad en la tierra come en el cielo. El reino de Dios es la situación en que los hombres reconocen efectiva y práricamente la paternidad - seflorio amoroso- de Dios sobre todos viviendo la fraternidad: las tres peticiones "santificado sea tu nombre, venga tu Reino, hágase w voluntad en la tierra como en el cielo" son como tres formas insistentes y superpuestas con las que pedimos siwarnos efectivamente ante Dios como Padre, viviendo la filiación en la fratemidad Maleo, además, coloca el Padre nuestro en el centro del Sermón de la Montaña, después de la proclamación del nuevo precepto del anor al prójimo: "Se dijo: amarás a tu projimo y odiaras a tu enemigo, pero yo les digo, amen a sus enemigos... para que sean hijos del Padre celestial, que hace salir su sol sobre buenos y malos, y hace llover sobre justos e injustos" (Mt 5, 43-46). Esto es lo que nos hace "hijos del Padre celestial", lo que pedimos en el Padre nuestro: amamos con un amor gratuito y total -fraternal- como el de Dios mismo, y no sólo con un amor interesado, como el que suponía la ley antigua. En esto el cristiano es invilado a semejarse a Dios en la total gratuidad del amor: "Sean, pues, perfectos como el Padre celestial es perfecto" (Mt 5, 48).

Parece que ya muy pronto se intentó interpretar el reino de Dios como una realidad meramente escatológica, como algo que aparecería al linal de los tiempos -y, en realidad, fuera del tiempo, de la historia - en la segunda venida de Jesús. Pero la predicación de Jesús acerca de la "cercanía" del reino, de la 
necesidad de la conversión y del seguimiento, de la santificación del nombre de Dios y del cumplimiento de su voluntad "así en la tierra como en el cielo", del amor a los enemigos o de la responsabilidad de los "talentos" recibidos, no permiten esa relegación del reino a lo puramente metahistórico. La realidad del reino comienza al menos a jugarse en este mundo, y lo que es el reino y la salvación ha de experimentarse en nuestro mundo en las nuevas relaciones de filiación-fraternidad en las que, en seguimiento de Jesús, nos colocamos "para ser hijos del Padre celestial'ms.

Sin negar los elementos apocalípticos importantes que se encuentran en las tradiciones evangélicas, hoy nadie puede alırmar que Jesús fuera un mero profeta apocalíptico que anunciara el juicio final —más o menos inminente- de Dios sobre la historia. Jesús proclama que con él comienza el reino de Dios aquf en la tierra, e invita a los suyos a que quieran seguirle en la tarea de hacer este reino de Dios real y efectivo, aunque sea con riesgo de muerte (Mt 16, 24-27; Mc 8, 34-38; Lc 9, 23-26, etc.). Jesús va por delante, revela el amor del Padre haciendo que se sientan acogidos por Dios pecadores y marginados. Asf comicnza a hacerse efectivo el reino de Dios en la tierra. Reconocer y aceptar el Dios que Jesús proclama como Padre de todos significa reconocernos como hermanos y comenzar a vivir una nueva forma de relación fraterna, en la cual el amor a Dios y al projimo se implican mutuamente. Los distintos aspectos de la predicación y de la acción de Jesús convergen admirablemente: revelar a Dios como Padre, proclamar la llegada del nuevo reino de Dios que reclama convertirse a él, y poner el mandamiento del amor como fundamento del nuevo reino, conduce lodo a lo mismo: reconocer y acoger efectivamente la Paternidad de Dios, viviendo la filiación en la fraternidad.

Algunos han hecho notar con extraffeza que el tema del reino solo parece estar presente en los sinópticos. En el resto de los escritos del Nuevo Testamento, particularmente en Pablo, parece haber casi desaparecido. Esto no es exactamente asi; lo que sucede es que Pablo ha traducido y traspuesto el tema del reino a categorlas en parte distintas, como son las de la "nueva creación" y de la "filiación adoptiva"; permanece empero la idea fundamental del reino predicado por Jesús: reconocer la patemidad de Dios, viviendo efectivamente la filiación-fraternidad por la fuerza del mismo Espiriu de Dios. La novedad de Pablo podría estar en haber formalizado más la consideración del reino en el marco de la acción trinitaria de Dios. Dios Padre envia a su propio Hijo (Gal 4, 4; $\mathrm{Rm} \mathrm{1,} \mathrm{3;} \mathrm{Fil} \mathrm{2,} \mathrm{5ss)} \mathrm{a} \mathrm{la} \mathrm{condición} \mathrm{humana} \mathrm{para} \mathrm{ser} \mathrm{"nuevo} \mathrm{Adán",} \mathrm{es} \mathrm{decir,}$ el "hombre nuevo" que ha de dar comienzo a una nueva humanidad, a una nueva forma de vivir los hombres en relación con Dios y entre sl (ver $R m 5,12$ 19; 1Cor 15, 21-22; Ef 2, 15 elc.). Lo que era el reino en los sinóplicos es en Pablo la "nueva creación" (2Cor 5, 17; Col 1, 15-20). Jesús es el iniciador entre los hombres de una "vida nueva", "en justicia y santidad" (EF 2, 10; 4, 24; Col $2,10)$, y nos invita a seguirlo3. Pero no seriamos capaces de hacerlo si no fuera 
porque el mismo espíritu de Dios, gracias a Jesús, ha sido infundido y derramado en nuestros corazones, haciéndonos hijos de Dios y dándonos fuerza para vivir en consecuencia ( $\mathrm{Rm} 8,14 \mathrm{ss} ; \mathrm{Gal} 4,4 \mathrm{ss}$ ).

Que la "nueva creación" que anuncia Pablo - como el reino que predicaba Jesús - no cs algo meramente metahistórico lo muestra su insistencia en hablar de la acción actual, histórica y permanense del Espíritu de Dios, derramado en nuestros corazones para transformamos desde y en nucstras condiciones históricas. Podríamos decir que la concepción paulina de la salvación no es la de que Dios aciúa como desde fuera, prometiendo una salvación ultramundana a los que logren escapar incontaminados del mundo (reduccionismo gnosticoescatológico); ni tampoco actúa meramente por una acción histórica limitada, a traves de un enviado que en un momento dado nos dirfa de parte de Dios lo que Dios quiere de nosotros (reduccionismo cristológico: Cristo supremo maestro y ejemplo); sino que la acción salvffica de Dios es permanente en la historia, a uraves de la permanente acción del Espíritu de Jesús "en los corazones de los hombres", es decir, desde su interior, desde el lugar donde surgen las opciones, los valores y las decisiones del hombre, y no por una proposición extrínseca de normas (legalismos, moralismos) y menos aún por coacción impositiva (represión, inquisición). Realmente no se puede dudar que Pablo, en su concepción de la acción salvadora de Dios Padre a través del "envio" del Hijo y de la "efusión" del Espíritu, pensaba en una salvación de la historia en la historia. en una transformación de la vida concreta e histórica de los cristianos, que anticipa de alguna manera la plenitud de comunión de vida a la que Dios nos llama más allá de la historia en la "resurrección."

Desde esta perspectiva se descubre todo el valor de las exhortaciones morales que llenan las cartas paulinas: no son nuevas formas de moralismo o legalismo en inconsciente y paradójica contradicción con el profesado antilegalismo del apóstol, sino expresión de las exigencias concretas e históricas de la nueva vida de filiación-fratemidad que el Espíitu hace nacer en el corazón de los que lo acogen. El gran principio paulino será el de que sólo puede salvar "la fe que se muestra operante en la caridad" (Gal 5,6), es decir, no una fe que meramente confiesa con la boca que hay un Dios allá en el cielo, sino la fe que reconoce efectivamente a Dios como Padre, reconociendo al Hijo que nos ha sido enviado con la fuerza del Espíritu que nos hace vivir como hijos viviendo como hermanos.

Por haber perdido de vista la dimensión trinitaria, y particularmente la dimensión pneumatológica, de la salvación cristiana, la teología occidental había llegado casi a perder del todo el sentido intrahistórico de la salvación, como liberación del hombre ya en la historia. Proocupados por establecer cómo Cristo ofrecía una satisfacción sustitutoria adecuada a un "Dios" abstracto ofendido, y considerando la acción del Espíritu como la acción de una fuerza "sanante" o "elevante" igualmente abstracta, la teologia tradicional de las escuelas habia 
llegado a olvidar la dimensión histórica de la salvación. Pero una lectura receptora de lo que Pablo quiere decimos no nos permite perdemos en abstracciones ahistoricas: para Pablo el pecado es una realidad histórica y concreta que afecta a los hombres concretos. A esta realidad histórica, Dios Padre envía a su Hijo, hecho hombre, quien vive la filiación y la fraternidad hasta la muerte. Por esto lo resucita y lo glorifica, mostrando así su poder salvador más allá de la muerte infligida por los que rechazan la oferta de una vida de hijos de Dios en la fraternidad. Pero no acaba ahí la acción de Dios en la historia: como elemento esencial de la glorificación del Hijo está la efusión de Espíritu del Hijo, que hace a los hombres hijos con el Hijo y hermanos entre sí. El Espíritu es la fuerza de Dios, liberadora de los hombres ya en este mundo. A los gálatas, agobiados y ahogados porque servian "a los que en realidad no son dioses" $(4,6)$, después de haberles anunciado la buena nueva de la efusión del Espíritu de fuliación, Pablo les grita: "¡Hermanos, han sido llamados a la libertad! Sólo que no han de tomar esa libertad como pretexto para sus egoísmos, sino al contrario, para servir por amor los unos a los otros. Pues toda la ley alcanza su plenitud en este solo precepto: amarás al prójimo como a ú mismo. En cambio si se muerden y devoran mutuamente, van a la ruina" $(5,13-15)$. He ahí la sínteis del programa salvador-liberador de Dios según Pablo: el cristiano ha de vivir en la libertad que le otorga el Espírit;; no ha de servir a los falsos poderes "que en realidad no son dioses", ni son según Dios; ni tampoco ha de entregarse a egoísmos y rivalidades insolidarias so pretexto de libertad. La libertad cristiana es la que el hombre alcanza cuando regula su vida por el único principio del amor al prójimo, que es la manera como práxicamente manifiesta su amor a Dios en este mundo. Si, por el contrario, los hombres no se mueven por el amor, sino que se devoran mutuamente en sus egoísmos, el apóstol avisa que para los hombres no puede haber más que nuina y destrucción en su misma historia mundana. Puede leerse todavía el final de este capítulo 5 de la carta a los Gálatas, donde el apostol describe los frutos hisı́ricos "de la came" (egolsmo pecaminoso) contrastados con los frutos contrarios del Espíitu: con pinceladas vigorosas y rápidas queda bosquejado lo que es la vida de los hombres destrozados y oprimidos por sus egoismos mutuos, y lo que Dios quiere que sea, bajo el influjo liberador del Espíritu, en la "nueva creación"37.

Asf, pues, Pablo no concibe la salvación como algo meramente metahistórico, sino como algo que transforma la existencia individual y social del hombre en su realidad histórica. Cristo nos salva no sólo del pecado como ofensa a Dios, sino del pecado como autodestrucción de la humanidad y rechazo del designio divino sobre la historia. Por esto Cristo no se limita a ofrecer al Padre una satisfacción vicaria condigna en favor de los hombres (como subraya la soteriología clásica), sino que envía su Espíritu permanentemente al mundo para transformarlo, para hacer de él "una nueva creación", restaurando el primigenio designio de Dios. El cristiano es salvado en la medida en que en su 
vida histórica concreta -en su actividad individual, familiar, social, política, econónica - se deja interpelar por el Espiritu que le lleva a vivir la filiación para con Dios en la fratemidad interhumana Toda la historia humana -individual y colectiva- ha de ser asf transformada y liberada por la fuerza salvadora de Dios que es el Espíritu. Si no hay esta transformación y liberación, es que estamos todavia en nuestros pecados, es que no dejamos que el Espíritu de Jesús se apodere de nosotros, sino que seguimos esclavos de nuestras concupiscencias y de nuestra came.

La salvación es asi toda don de Dios, a través de Jesús, por la fuerza de su Esplritu; pero es toda tarea nuestra que hemos de realizar con nuestra lucha, dejándonos llevar por el Espíritu de Dios ( $R m$ 8, 14) y no por nuestras concupiscencias, "progresando siempre, fimnes e inconmovibles en la obra del Sefior, sabiendo que nuestro esfuerzo no es vano en el Sefior" (1Cor 15, 58). Es a través de esta lucha y este esfuerzo liberador por el que nos liberamos y liberamos nuestro mundo y nuestra historia de la esclavitud tiránica de los egoísmos mutuos, como "es preciso que El reine hasta poner a wodos sus enemigos bajo sus pies" (1Cor 15,25 ). Pablo cree asi en la salvación y en la liberación históricas: pero no reduce la salvación y la liberación a sus dimensiones historicas y visibles. El pecado, con sus consecuencias, ha entrado en el mundo; "la creación ha estado sometida a frustración" ( $R m$ 8, 20): no es posible hacer que esto no haya sido, aunque es posible vivir en "la esperanza de ser liberados de la servidumbre de la corrupción, para participar en la gloniosa libertad de los hijos de Dios" (Rm 8, 21). El mundo es como un campo de lucha entre el pecado que da muerte a los hombres -y al mismo Dios hecho hombro- y el Espiritu por el cual los hombres encuentran la vida, reconociêndose libre y amorosamente como hijos de Dios y como hermanos unos de otros ${ }^{38}$. "El úlimo enemigo en ser destruido será la muerte" (1Cor 15, 26), lo cual quiere decir que el pecado tendrá fuerza mortal mientras persista, porque el amor y la libertad en la filiación-fraternidad no pueden imponerse por la fuerza. Dios no quiere reinar con la falsa gloria de los tiranos que someten a la fuerza. Cristo sera Sefior cuando, una vez que se haya manifestado cómo todo lo que es contra Dios sólo lleva a la muerte, se manifieste que tiene poder para dar vida a todos los que son de Dios y hacer que Dios "sea todo en todos" (1Cor 15, 28). La creación sufre un penoso proceso de dolor, de frustración y de muerte, porque el hombre rechazo el designio de Dios sobre ella. Pero, a través de Jesús, Hijo de Dios hecho hemano nuestro, solidario con nosotros en todo, y a través de la perenne efusión de su Espiritu en los que se disponen a seguirlo. Dios testifica su voluntad de recuperar el sentido de la primigenia creación; nos interpela a que lo reconozcamos como Padre, amándonos como hermanos; a que nos liberemos de la opresión y destrucción mutua provocada por nuestros egorsmos pecadores, para que "venga su reino en la tierra como en el cielo"; nos invila a que ya desde aqui vivamos el gozo de la comunión en el amor, a semejanza del 
gozo de la eterna comunión amorosa que es la vida misma de Dios, Padre Hijo y Espíritu, en la cual estamos llamados a participar por don suyo. La creación recupera el sentido originalmente querido por Dios en la medida en que los hombres hacen de ella un ámbilo de comunión, a imagen de la comunión trinitaria. Por eso, la suprema oración de Jesús fue "que todos sean uno, como tá Padre en ml y yo en ti: que sean uno en nosotros" (Jn 17, 21-22). Y nuestra suprema responsabilidad es vivir esta comunión efectivamente, en rodas las formas posibles, en nuestra condición histórica, mientras esperamos verla consumada plenamente más allá de la historia ${ }^{39}$.

\section{Notas}

1. H. Urs von Balthasar, Schopfung und Trinith Insernationale Katholische Zeitschrift Communio, 17 (1988), 205-214.

2. L. Scheffczyk, Creación y Providencia (Hivioria de las Dogmas II-2), Madrid, BAC, 1974.

3. Puede verse particularmente: Is 42,$5 ; 43,1 s s ; 44$, 1ss; 45,$12 ; 51,12-13$, etc.

4. Por ejemplo Amos 4, 12ss; 5, 8ss; 9, 5-7; Mal 2, 10; Jr 33, 25: "Como es cierto que cree el día y la noche, y establect las leyes de los cielos y la tierra, tambien es cierto que no rechazare el linaje de Jacob". Tambien $P s$ 14, 33; 74, 89; 203, etc.

5. W. Kem, "La creación como presupuesto de la alianza", en Mysreriun Saluris I/1, Madrid, 1969, pág. 490. Este trabajo se recomienda como una excelente síntesis de los elementos biblicos y tradicionales acerca del sentido trinitario y cristológicosalvifico de la revelación sotre la creación. El que modernemente mits he contribuido a esta orientación he sido $\mathrm{K}$. Barth con su famosa formulación: "Le creación es el fundamento externo de ia alianze, mientras que Esh es el fundamento interno de la creación (Kirchliche Dogmatit, II/1, 103; que es como decir que la creación tiene prioridad histórica respecto al pacto, pero el pacto tiene priơridad lógica). La única explieación de la creación es la voluntad divina de comunicarse gratuita y amorosamente. Esto no implica que hayamos de seguir a Barth en su radical negación del valor de la naturaleza y de la "teologin nanum". Existe la naturaleza con su valor: pero su pleno sentido no se descubre sino cuando se revela la voluntad gratuita de Dios de manifestar en elle su gloria a través de la salvación en Cristo.

6. He desarrollado la contraposición entre el principio de necesidad (propio de la filosofía que procede por rationes necessariae) y el de granidad (propio de la acción de Dios) en mi arúculo: "Dios, ¿principio de necesided o interpelecion absoluta a la libertad?" Revista Latinoumericana de Teologia (1987), 177-195.

7. En este sentido este modesto trabajo quisiere ayudar, aunque sea a modo de sugerencia, a ampliar los campos habituales de reflexión de la reologin de la liberación: éstos han sido más habitualmente los de le teologie del éxodo y la alianza, la cristologfa y la eclesiologia Quisiéramos mostrar oomo en la misma teologfa trinitaria, y en la teologla de la creación que en ella radica, hay una exigencia de praxis liberadora

8. Los principales texlos del Nuevo Testamento sobre la creación potrian ser: $1 \mathrm{Cor} 8$, 
6ss; 15, 45-49; Col 1, 15-20; E[ 1, 10-22; 4, 8-10; Heb 1, 2-4; 11, 3; Jn 1, 1-4; 5 . 19-20.

9. El Espíritu Santo no aparece tan expllcitamente en los otros textos que hablan más bien de que Dios lo creo todo por y para Cristo. Esto parece sugerir que se trata de texios marcados por una teologia muy primitiva, en la que no se habia reflexionado sobre la función del Espíritu. Pero Pablo concluirá que la reconciliación de todo y la filiación proviene de Cristo por el don del Espíriu: véase, por ejemplo. Rm 8, 5 27; Gal 4, 6-7; 5, 13-26; 1Cor $12,4-11$, etc.

10. Puede verse la hiscoria de la reflexión teológica sobre la cteación en la obra de $\mathrm{L}$. Scheffczyk, citada en la nota 2. Tambiên más sucintamente, en W. Kern, "El creador es el Dios uno y trino", Mysterium Salutis II/1, Madrid, 1969, 528 ss.

11. De Fide Orthodoxa I. 2, p. 94, 864.

12. 1.c., p. 210.

13. De Trinisate $1,2,4 ; 4,7 ; 5,8$, etc.

14. Puede verse la presentación de la teología trinitaria de Agustín que ofrezco en mi libro: Si oyerais su vor, Santander, Sal Terrae, 1988, cp. 15. También H. Muthlen, "¿Acníar las personas divinas como tales en el ámbilo de lo creado?". Selecciones de Teologia, 62 (1977), 127-139.

15. Conira Sermonem Arianorum 3, 4: PL 42, 685.

16. De Trinitase I, 12, 25.

17. Ibid., I, 12, 25.

18. Contra Sermonem Arianorwm 15: PL 42, 586.

19. De processione Spiritus Sancti, 18.

20. DB 703. El Concilio IV de Letrán, DB 428, proclama la le en la Trinidad, pero habla de la creación como obra de un solo prixcipio, sin referencia a las personas divinas: "Uno solo es el verdadero Dios... Padre, Hijo y Espíritu Santo: tres personas ciertamenle, pero una sola esencia, sustarcia o naturaleza.. un solo principio de todas las cosas, Creador de todo..." El Concilio Vaticano I dirá, sin referencia alguna a la Trinidad, que "Este solo verdadero Dios, por su bondad y virtud omnipotente... cré de la nada.. DB 1783. Realmente, la perspectiva trinitaria y salvífica de la creación parecía haber desaparecido de la teología calólica latina

21. Ad Serapionem, 1, 28. Esta es la manera habiual de hablar en los teólogos griegos, por ejemplo, Ireneo, Adversus Haereses IV, 20, 1; 38, 3; Gregorio de Nisa, Que no hay tres dioses, PG 45, 125.

22. Esudes de Theologie pasitive sur la Sainse Trinile, Paris, 1898, IV, 459. Ver Lambien L. Bouyer, Le consolatew, Peris, 1986, 218. El P. W. J. Hill, The Three Personned God, Washington, 1982, 53ss., llege a hablar de un "criptomodalismo occidental", el cual, aunque confiesa la trinidad de personas, considera la acción ad extra de Dios exclusivamente como acción de la esencia divina única e indiferencjada.

23. Summa Théologica I, 32, lc. Igualmente dice en I Sent 5,1ml: Essentia creat et gubernat.

24. Ibid., 45,6 .

25. Ibid., 1, 32,1 ad 1. Semejante en I. Sens 14, 2, 2 dice: “Así como... el brotar de las personas es el fundamento del brotar de las criaturas del primer principio, así aquel mismo brotar es el fundamento de su regreso al fin; pues por medio del Hijo y del 
Espíritu Santo no solo somos conslituidos originariamente, sino vinculados tambiên al fin último".

26. In Hexaemeron 1, 16 (edición de Quaracchi, V, 332).

27. Ibid., 11, 13 (Quaracchi V, 382).

28. M. Oitra. Obras de San Buenaventwa, vol V. Introducción, Madrid, BAC, 1948, pp. 29-30. Un discípulo de Buenaventura. Mateo de Aquasparta, llegó incluso a proponer una especie de deducción racional de la Trinidad a partir de la creación, por cuento una producción "hacia afuera", necesariamente imperfecta, presuponía una producción perlecta "hacia dentro". Ver 2. Hayes. The general Doctrine of Creation in the Thirteensh Censury, with special emphasis on Mashew of Aquasparla, Murich, 1964.

29. P. Trigo, Creación e historia en el proceso de liberación, Madrid 1988, 217 (colección Cristianismo y sociedad, 13). En contraste podernos percibir que se quedó corto el Concilio Varicano I al declara que Dios creo "para manifestar su gloria", sin referirse para nada a la Trinidad y sin explicitar que "se trata de la gloria al Padre, por el Hijo, en el Espíritu, como repetía la parrística griega". Véase L. Amendáriz, "Fuerza y debilidad de la dactrina del Vaticano I sobre el fin de la creación", Estudios Eclesí́sticos 45 (1970), 385.

30. A. Colzani, Diccionario Telógico Interdisciplinar, arlículo "Creación", Salamanca, 1985, I, 724.

31. Teologla del Antiguo Testamenso, Salamanca 1982 (5), I, 202-203. Hablando del Deuteroisaías dice el mismo autor, ibid., L, 302: "no ve la creación como un hecho en sí al margen del obrar histórico. Parece no distinguirlos claramente". Por esto, el profeta juega con la idea de que el "creador de Israel" es el "creador de los cielos y la tierra". Esta expresión "cielo y lierra" es el equivalente bíblico de "cosmos", pero se dislingue porque se mantiene en un nivel descriptivo sin implicar una Lotalidad global y ya plenamente estructurada.

32. El sentido de la historia, Barcelone, 1936, 47. Las profundas intuiciones de Berdiaeff sobre el fundamento trinitario de la creación han sido comentadas por $\mathrm{J}$. Molonanr, Trinidad y Reino de Dios, Salamanca, 1983, 57ss.

33. A Torres Queinuga, La revelación de Dios en la realización del hombre, Madrid, $1987,188$.

34. Teologia políica, San Salvador, 1973, 7. Posleriormente, el mismo autor volvió sobre el tema en "Historicidad de la salvación critiana", Revista Latinaamericana de Teologla, $I$ (1984), 5-45.

35. El reduccionismo escatológico del reino aparece no sólo cuando se aplaza la salvación a un más allá de la historia que en realidad dejarfa intocada la historia, sino cuando de lal manera la salvación es aco de sólo Dios que la acción del hombre results irrelevante. Este es el reproche que en algunos momentos podría hacerse a K. Barth; o también al existcncialismo de R. Bultmann, para quien en Cristo habría parecido el eschaton de tal manera que la hisoria habría quedado abolida y sólo restaría adherirse por la fe a aquel eschaton.

36. Pablo habla a veces del reino de Dios como de aquella realidad cristológica que los injustos no pueden heredar (1Cor 6, 9; 15, 50; Gal 5. 21; Ef 5. 5; 2Tes 1, 5). Pero otras veces habla del reino en su dinensión intrahisbórica Asi, $\operatorname{Rm} 14,17$, en el contex b de la polémica sobre los alimentos impuros: "El reino de Dios no es comida ni bebida, sino justicia, y paz y gozo en el Espíritu Santo; quien asi sirve a 
Cristo se hace grato a Dios y merece la aprobación de los hombres". Y a los corintios díscolos los inctepa, "El reino de Dios no es cosa de palabrerfa, sino de poder de Dios" (1Cor 4.20).

37. Brevemente quieto indicar que el Espíritu tiene en Juan funciones análogas a lis que le atribuye Pablo, annque expresadas en las categorfas propias del cuaro ovangelio. Asl, cuando Jesús dice que el Esplritu guiará a los suyos "hasla la vaded complekn" (Jn 16, 13); o que les "enseñará codo y les recordará codo lo que les ha dicho" (Jn 14, 26); o que "dará testimonio de $m \Gamma$ " (Jn 15, 26), no hay que entender estes expresiones en un sentido meramente noético, o de ilustración y recuerdo meramente inteleculal, sino en el sentido de que el espíritu hará existencialmente significativas y operantes las enserianzas de Jesús.

38. Deade este óptich estrictamente teológica, hay que decir que estando toda la creación orientedn hacie un único designio divino, no parece procedente distinguir toologicemente entre una "historis prolana", que neda tendría que ver con la sajvecion, y un "historie alvifica", de hechos salvadores, a la manera como lo hace. por ejemplo, K Lowith cuando dice: "A la luz de la fe los eventos mundanos de sites y desputs de Cristo no establecen sucesión alguna continuada de aconLecimientos significentes, sino tan sólo el marco externo del acontecer salvífico" (Weiggeschiche und Heilsgeschehen, 1953, 169). Salvando la auwnomía de las realidades tertenas ul como la explica el último concilio (Gaudium et Spes, 36), y salvendo el hecho de las intervenciones salvflieas de Dios en la historia mundana, no parece adecuado concebir la historia de la salvación como una suprahistoria al margen de la historia profana, reducida a mero "marco extemo del acontecer alvifico". Muy al contrario, los hechos salvificos (promesas, encarnación, efusión del Esplitu...) inciden en el corazón mismo de la historia humana transformbindola interionmense. En todo lo que el hombre hace, obra según el designio de Dios o contra th, y por tmto, obra salvación o condenación. Dios no opera la alvación en un umbito distinto al de la historin humana. Ciertamente, la salvación no ve reduce al proceso inmanente de la historia (lleno de pecado o de simple cotupidez), pero tampoco se da fuera de este proceso (precisamente porque se da como reacción contra el pecado o el sinsentido del mismo). Ver, J. Vives, G. Gutitrez, "Por una liberación cristiana", Revisia Latinaamericana de Teologia, 3 (1984), 334; W. Pennenberg, Cuestiones Fundamentales de Teología Sistemática, Salamance, 1976, 227.

39. La experiencia de los místicos parece anticipar algo de lo que pueda set esta conounación. No resisto reproducir un texto de San Juan de la Cnuz en el comentario del verso "El aspirar del aire": "con aquella su aspiración divina muy subidamente Dios leventa el alma y la informa y habilita para que ella aspire en Dios la misma aspiración que el Padre aspira en el Hijo, y el Hijo en el Padre, que es el mismo Esplritu Santo... Porque no seria verdadera y total transformación si no se transformase el alma en las tres personas de la Santísima Trinidad... y no hay que tene por imposible que el alma pueda una cosa tan alta, que el alma aspire en Dios como Dios aspira en ella, por modo participado... ¿Qué increfble cosa es que obre ella tambien en obra de entendimiento, noticia y amor, o, por mejor decir, la tenga obrada en la Trinidad, juntanente con ella, como la misma Trinidad? Pero por modo comunicado y participado, obrándolo Dios en la misma alma... Y para que pudiera venir a esto la crió a su imagen y semejanza", (Cántico Espiritual, A, 39). 